\title{
Roles of Semaphorin-6B and Plexin-A2 in Lamina-Restricted Projection of Hippocampal Mossy Fibers
}

\author{
Hiroshi Tawarayama, ${ }^{1,2}$ Yutaka Yoshida, ${ }^{3,4}$ Fumikazu Suto, ${ }^{5,6,7}$ Kevin J. Mitchell, ${ }^{2}$ and Hajime Fujisawa ${ }^{1}$ \\ ${ }^{1}$ Division of Biological Science, Nagoya University Graduate School of Science, Chikusa-ku, Nagoya 464-8602, Japan, ${ }^{2}$ Smurfit Institute of Genetics, and \\ Institute of Neuroscience, Trinity College Dublin, Dublin 2, Ireland, ${ }^{3}$ Howard Hughes Medical Institute, Department of Biochemistry and Molecular \\ Biophysics, Center for Neurobiology and Behavior, Columbia University, New York, New York 10032, ${ }^{4}$ Division of Developmental Biology, Cincinnati \\ Children's Hospital Medical Center, Cincinnati, Ohio 45229, 5 Division of Developmental Neuroscience, Center for Translational and Advanced Animal \\ Research, Tohoku University Graduate School of Medicine, Sendai, 980-8575, Japan, ${ }^{6}$ Division of Developmental Genetics, National Institute of Genetics, \\ Mishima 411-8540, Japan, and ${ }^{7}$ Core Research for Evolutional Science and Technology, Japan Science and Technology Agency, Kawaguchi 332-0012, Japan
}

Hippocampal mossy fibers project preferentially to the proximal-most lamina of the suprapyramidal region of CA3, the stratum lucidum, and proximal-most parts of the infrapyrmidal region of $\mathrm{CA3c}$. Molecular mechanisms that govern the lamina-restricted projection of mossy fibers, however, have not been fully understood. We previously studied functions of neural repellent Semaphorin-6A (Sema6A), a class 6 transmembrane semaphorin, and its receptors, plexin-A2 (PlxnA2) and PlxnA4, in mossy fiber projection and have proposed that PlxnA4-expressing mossy fibers are principally prevented from entering the Sema6A-expressing suprapyramidal and infrapyramidal regions of CA3 but are permitted to grow into proximal parts of the regions, where repulsive activity of Sema6A is competitively suppressed by PlxnA2 (Suto et al., 2007). In the present study we demonstrate that Sema6B, another class 6 transmembrane semaphorin, is expressed in CA3 and repels mossy fibers in a PlxnA4-dependent manner in vitro. In Sema6B-deficient mice several mossy fibers aberrantly project to the stratum radiatum and the stratum oriens. The number of aberrant mossy fibers is increased in Sema6A;Sema6B double knock-out mice, indicating that Sema6A and Sema6B function additively to regulate proper projection of mossy fibers. PlxnA2 does not suppress the Sema6B response, but itself promotes growth of mossy fibers. Based on these results, we propose that the balance between mossy fiber repulsion by Sema6A and Sema6B and attraction by PlxnA2 and unknown molecule(s) prescribes the areas permissive for mossy fibers to innervate.

\section{Introduction}

In the hippocampus, afferents from various brain regions terminate at specific laminae. In CA3, fibers from the entorhinal cortex terminate at distal parts of the suprapyramidal region [the stratum lacunosum-moleculare (SLM)]; axons from CA3 pyramidal cells of both the contralateral and ipsilateral sides terminate at middle parts of the suprapyramidal region [the stratum radiatum (SR)] and at the stratum oriens $(\mathrm{SO})$ in the infrapyramidal region; and axons of dentate granule cells, mossy fibers, innervate at proximal-most parts of the suprapyramidal region (the stratum lucidum) to form the suprapyramidal bundle and proximal-most parts of the infrapyramidal

Received Jan. 5, 2010; revised March 17, 2010; accepted April 10, 2010.

This work was supported by Grants-in-Aid from the Ministry of Education, Science, Sports, and Culture of Japan Ministry of Education (H.F.), grants from the $21{ }^{\text {st }}$ (entury COE Program (H.T. and H.F.), Grant-in-Aid for Young Scientists (B) and CREST (Core Research for Evolutional Science and Technology) of Japan Science and Technology Agency (F.S.), National Institutes of Health Grant R01 NS065048 (Y.Y.), and a Health Research Board Project Grant (K.J.M.). Sema6B mutant mice were generated in, and generously provided by the Dr. T.M. Jessell Laboratory, at Columbia University (New York, NY). We also thank Drs. M. Mendelsohn, J. Kirkland, and B. Han (Columbia University) in the generation of the Sema6B mutant mice, and Dr. J. Miyazaki (Osaka University, Suita, Japan) for pCAGGS expression vector.

Correspondence should be addressed to Hajime Fujisawa, Division of Biological Science, Nagoya University Graduate School of Science, Chikusa-ku, Nagoya 464-8602, Japan. E-mail: hcfujisawa@mf.ccnw.ne.jp.

DOI:10.1523/JNEUROSCI.0073-10.2010

Copyright $\odot 2010$ the authors $\quad 0270-6474 / 10 / 307049-12 \$ 15.00 / 0$ region of CA3c to form the infrapyramidal bundle (Amaral and Witter, 1995).

Several attractive and repulsive molecules, such as netrin-1 (Barallobre et al., 2000), RGMa (Brinks et al., 2004), Eph ligand ephrins (Stein et al., 1999; Otal et al., 2006), class 3 semaphorins (Chédotal et al., 1998; Steup et al., 1999, 2000; Cheng et al., 2001; Pozas et al., 2001; Bagri et al., 2003; Liu et al., 2005), Slit-2 (Nguyen-Ba-Charvet et al., 1999), and Reelin (Borrell et al., 2007), and cell adhesion molecules (Cremer et al., 1997; Förster et al., 1998) have been shown to take part in the guidance and termination of hippocampal afferents at proper laminae (for review, see Skutella and Nitsch, 2001). Molecular mechanisms that govern lamina-restricted projection of mossy fibers, however, have not fully been elucidated.

We have previously shown that Semaphorinn-6A (Sema6A), a neural repellent of the class 6 transmembrane semaphori, and its receptors plexin-A2 (PlxnA2) and PlxnA4 play crucial roles in lamina-restricted projection of mossy fibers (Suto et al., 2007). On the basis of projection patterns of mossy fibers in Sema6A, PlxnA2, PlxnA4 knock-out mice and double knock-out mice for these genes, we have proposed that mossy fibers express PlxnA4 and are prevented from innervating Sema6A-abundant suprapyramidal and infrapyramidal regions of $\mathrm{CA} 3$, but they are permitted to grow into proximal-most parts of these regions, where the repulsive activity of Sema6A is attenuated by PlxnA2 (Suto et al., 
2007). On the other hand, the finding that mossy fibers spread into inappropriate laminae of CA3 in PlxnA4 mutants, while projecting to the normal target lamina in Sema6A mutants and PlxnA2;Sema6A double mutants (Suto et al., 2007), suggested the existence of additional PlxnA4-related mossy fiber repellent(s) in CA3.

We have reported that Sema6B, another class 6 semaphorin, repels sympathetic axons and that the repulsive activity of Sema6B is mediated by PlxnA4 (Suto et al., 2005). Here, we report that Sema6B is expressed in CA3 and functions as a repellent for mossy fibers. We generate protein-null mutant mice for Sema6B and Sema6A;Sema6B double knock-out mice and demonstrate that Sema6B functions additively with Sema6A to regulate proper projection of mossy fibers. In addition, we show that PlxnA2 does not suppress the Sema6B response but itself promotes growth of mossy fibers. Based on the findings obtained in the present and previous studies (Suto et al., 2007), we discuss how Sema6A and Sema6B and their receptors, PlxnA2 and PlxnA4, work in concert to regulate proper projection of mossy fibers.

\section{Materials and Methods}

Generation of mice lacking Sema6B. Mouse genomic clones were derived from a 129/Sv genomic library (Stratagene). A targeting vector was constructed using a $9 \mathrm{~kb}$ NotI-BglI (NotI is derived from the phage DNA, and BglI was added just before the sequences corresponding to the first methionine) fragment and a $3 \mathrm{~kb}$ BamHI-SalI (SalI is derived from the phage DNA) fragment. The LoxP-PlxnA4PGKneo-triple pA signal-LoxP cassette and the farnesylated EGFP-pA cassette (where PGK is phosphoglycerate kinase and EGFP is enhanced green fluorescent protein) were inserted between the NotI-BglI and BamHI-SalI fragments. A linearized targeting construct was electroporated into 129Sv/Ev-derived embryonic stem (ES) cells. Cells were selected with G418 and screened by Southern blot analysis. Southern blot analysis was done on the EcoRI fragments of genomic DNA using a $0.5 \mathrm{~kb}$ fragment as a probe (see Fig. $1 \mathrm{~A}$ ) that generates a $14 \mathrm{~kb}$ wild-type band and an $8 \mathrm{~kb}$ mutant band. The ES cells carrying the correct mutation were injected into C57BL/6J blastocysts. Chimeric offsprings were mated with C57BL/6J mice. Germ line transmission of the mutant allele was determined by Southern blot analysis of genomic DNA from tails of mice. Heterozygous F1 animals were intercrossed to obtain homozygous $\left(\mathrm{Sema6B}^{-1-}\right)$ mice. Genotypes of mice were determined by PCR using the following primers: P1 ( $5^{\prime}$ CTCACATGTGGTCTTAAAGTCGCTTG- $3^{\prime}$ ) and P2 (5'-TGATATCGCAGCTCCGTGGAAGTGG-3') for the wild-type allele and P1 and neo-4 (5'-CCTGATCGACAAGACCGGCTTC-3') within the neomycin resistance gene for the mutant allele (see Fig. $1 A$ ). Amplification of DNA was performed using Ex-TaqDNA polymerase (Takara).

Animals. Sema6A;Sema6B double knock-out mice and PlxnA2; Sema $6 B$ double knock-out mice were generated by crossing Sema $6 B$ mutant mice with Sema6A mutant mice (Leighton et al., 2001; Mitchell et al., 2001) and PlxnA2 mutant mice (Suto et al., 2007), respectively. Noon on the day on which a copulation plug was found was designated as embryonic day 0.5 (E0.5). The day of birth was designated as postnatal day 0 (P0). All animal experiments and animal care were performed along with the guidelines of the Animal Care and Experimentation Committee of each institution.

Immunoblot analysis, histology, and in situ hybridization analysis. Immunoblot analysis using goat anti-human Sema6B antibodies $(0.2 \mu \mathrm{g} /$ $\mathrm{ml}$; R \& D Systems) was done on the extract of E16.5 mouse embryonic brains following the procedures reported (Shimizu et al., 2000). General procedures for Timm staining and immunohistochemistry have been reported previously (Suto et al., 2007). In this study, rabbit calbindin D-28k antibodies (Swant), rabbit calretinin antibodies (Swant), and an Armenian hamster monoclonal antibody for mouse PlxnA4 Mab-A4F5 (Suto et al., 2007) were used as primary antibodies. The calbindin and calretinin antibodies were detected by biotinylated anti-rabbit IgG (GE Healthcare) and a Vectastain ABC kit (Vector Laboratories), and the
PlxnA4 antibody was detected by Cy3-conjugated goat anti-Armenian hamster IgG (Jackson ImmunoResearch Laboratoryies). In situ hybridization (ISH) was performed by using the digoxygenin-labeled cRNA that corresponds to $1-833$ bases of the mouse Sema6B cDNA (GenBank accession no. NM_013662) as a probe, following the procedures reported (Murakami et al., 2001; Suto et al., 2003).

Culture of hippocampal slices. Organotypic culture of hippocampal slices was performed following the procedures reported previously (Mizuhashi et al., 2001; Suto et al., 2007).

Transfection of cultured pyramidal cells. To construct the expression plasmid for myc-tagged full-length Sema6B (myc-full-Sema6B), the sequences encoding the myc epitope were added at the $3^{\prime}$-end of the signal sequences of the Sema6B cDNA. The expression plasmid contained the Kozak-like sequences in the $5^{\prime}$-untranslated region (UTR) and the 3'-UTR (see GenBank accession no. NM_013662). The myc-tagged Sema6B cDNA was ligated into an expression vector pCAGGS (pCAGGS-myc-full-Sema6B; pCAGGS, a gift from Dr. J. Miyazaki, Osaka University, Suita, Japan). Hippocampal neurons from E16.5 mouse embryos were cultured for $4 \mathrm{~d}$, following the procedures reported (Goslin et al., 1998; Suto et al., 2007), and cotransfected with the pCAGGS-myc-full-Sema6B and an EGFP expression plasmid, pEGFP-N1 (Clontech), using Lipofectamine 2000 (Invitrogen). At $24 \mathrm{~h}$ after the transfection, cultures were fixed with $4 \%$ paraformaldehyde (PFA) and then immunostained with rabbit anti-myc antibody A-14 (Santa Cruz Biotechnology) and a mouse monoclonal antibody for MAP2 HM-2 (Sigma). To detect the antibodies A-14 and HM-2, Alexa Fluor 546-conjugated goat anti-rabbit IgG (Invitrogen) and Alexa Fluor 488-conjugated goat anti-mouse IgG (Invitrogen) were used as secondary antibodies, respectively.

Production of recombinant proteins. To construct the expression plasmids, pCAGGS-Sema6Bect-Fc-His ${ }_{6}$ for the Fc-dimerized ectodomain of Sema6B (Sema6Bect-Fc) and pCAGGS-AP-Fc-His ${ }_{6}$ for Fc-dimerized alkaline phosphatase (AP-Fc), the sequences corresponding to the 26599 amino acid residues of the mouse Sema6B protein and the 38-528 amino acid residues of the human placental alkaline phosphatase protein were inserted into the pCAGGS-Sema3Ass-Myc-Fc-His ${ }_{6}$ vector (Suto et al., 2007), respectively. Generation of the expression plasmids pCAGGS-Sema6Aect-Fc-His ${ }_{6}$ for the Fc-dimerized ectodomain of Sema6A (Sema6Aect-Fc) and pCAAGGS-PlxnA2SD-Fc-His for the sema domain of PlxnA2 (PlxnA2SD-Fc) were reported previously (Suto et al., 2007). Human embryonic kidney 293T (HEK293T) cells were transfected with pCAGGS-Sema6Aect-Fc-His ${ }_{6}$, pCAGGSSema6Bect-Fc-His $_{6}$, pCAAGGS-PlxnA2SD-Fc-His ${ }_{6}$, or pCAGGS-AP-

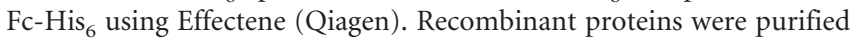
from culture supernatants using Ni-NTA (nickel-nitrilotriacetic) agarose (Qiagen) and dialyzed against Dulbecco's calcium- and magnesiumfree PBS for $2 \mathrm{~d}$.

Growth cone collapse assay. Small fragments of the dentate gyrus from P2 mice were cultured with NB/B-27 medium (Invitrogen) in 8-well chamber slides (Nunc) that had been coated with poly-L-lysine (PLL, 100 $\mu \mathrm{g} / \mathrm{ml}$; Sigma) and mouse laminin (10 $\mu \mathrm{g} / \mathrm{ml}$; Invitrogen). On the second day of cultivation, Sema6Aect-Fc recombinant proteins or Sema6Bect-Fc recombinant proteins were added to the cultures for $1 \mathrm{~h}$ at $37^{\circ} \mathrm{C}$. The cultures were fixed with PFA and processed for immunohistochemistry with calbindin antibodies to detect mossy fibers.

Competition assay. To examine effects of PlxnA2 on the Sema6A- or Sema6B-induced growth cone collapse in mossy fibers, Sema6Aect-Fc recombinant proteins or Sema6Bect-Fc recombinant proteins $(20 \mathrm{~nm}$ each) were preincubated with PlxnA2SD-Fc recombinant proteins or AP-Fc recombinant proteins (200 nM each) in NB/B-27 medium for 30 $\min$ at $37^{\circ} \mathrm{C}$. The protein mixtures were then applied to explant cultures of the dentate gyrus to examine their growth cone collapse activities; half volume of the culture medium was replaced with the protein mixtures.

Ligand-absorption assay. To examine interaction of Sema6A and Sema6B to PlxnA2 and PlxnA4, Sema6Aect-Fc recombinant proteins (2 $\mathrm{nM})$ or Sema6Bect-Fc recombinant proteins ( $20 \mathrm{~nm}$ ) were added to suspension cultures of $1 \times 10^{7} \mathrm{PlxnA2}$-expressing L cells (LA2 cells) (Suto et al., 2007), PlxnA4-expressing L cells (LA4 cells) (Suto et al., 2003), or parental $\mathrm{L}$ cells in $1 \mathrm{ml}$ of NB/B-27 medium and gently agitated for $1 \mathrm{~h}$ at 


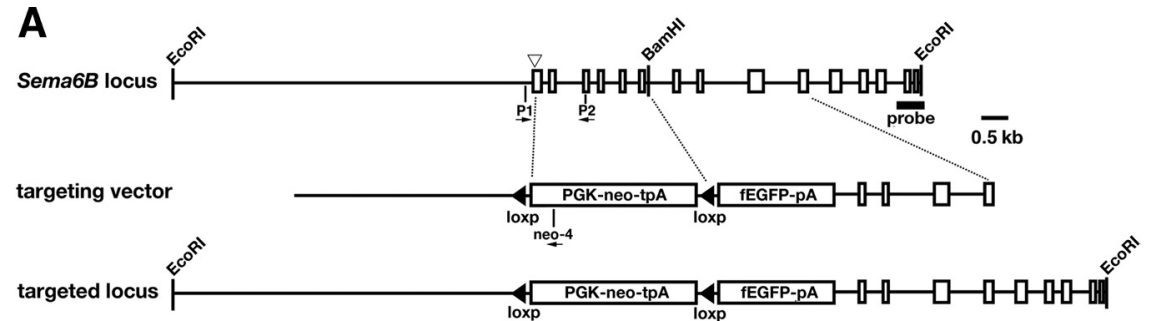

B

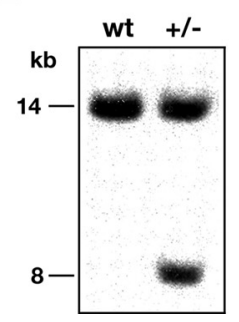

C

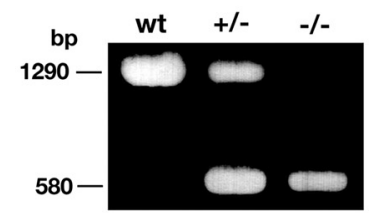

D

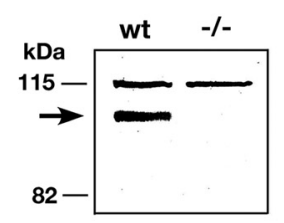

Figure 1. Generation of Sema $6 B$ mutant mice by targeted disruption of the Sema6B gene. $A$, Schematic illustration of the Sema6B gene (Sema6B locus), the targeting vector, and the targeted locus. Exons are indicated by boxes. The exon 1 in the $5^{\prime}$ upstream is omitted in the scheme. $\nabla$, Position of the initiation codon in the exon 2, ATG; PGK-neo-tpA, PGKneo-triple poly(A) casette; fEGFP-pA, farnesylated EGFP-poly(A) cassette. $\boldsymbol{B}$, Southern blot analysis on the EcoRI-digested genomic DNA from targeted ES cells, using a 3' external probe (probe in $\boldsymbol{A}$ ). Note that expected sizes of DNAs, $14 \mathrm{~kb}$ for the wild-type (wt) allele and $8 \mathrm{~kb}$ for the targeted allele, are detected. C, PCR analysis using primers, P1, P2, and neo-4 in A. Expected sizes of DNAs, $1.3 \mathrm{~kb}$ for the wild-type allele and $0.6 \mathrm{~kb}$ for the mutant allele, are amplified in animals derived from Sema6B heterozygous intercrosses. D, Immunoblot analysis using goat anti-human Sema6B antibodies. A band for the Sema6B proteins is detected at $100 \mathrm{kDa}$ position (arrow) in the extracts of brains from E16.5 wt but not Sema6B homozygous (-/-) mouse embryos. A band at $115 \mathrm{kDa}$ position is a nonspecific binding of the antibody.

$4^{\circ} \mathrm{C}$. The culture supernatants were collected by centrifugation and then applied to explant cultures of the dentate gyrus to examine their growth cone collapse activities; half volume of the culture medium was replaced with the supernatant.

Generation of 3 T3 cells that stably express transgenes. NIH3T3 cells were cotransfected with the expression plasmids for myc-tagged full-length mouse Sema6B (Suto et al., 2005) or PlxnA2 (Suto et al., 2007) and pST-neoB (Katoh et al., 1987) using Effectene, and selected with Geneticin (700 $\mu \mathrm{g} / \mathrm{ml}$; Invitrogen). Cell clones that express Sema6B (6B/3T3) or PlxnA2 (A2/3T3) were identified with a mouse monoclonal antibody for myc 9E10 (Evan et al., 1985). To isolate cell lines that doubly express PlxnA2 and Sema6B (A2::6B/3T3 cells), 6B/3T3 cells were transfected with the PlxnA2 expression plasmid and pCEP4 (Invitrogen), selected by hygromycin B (100 $\mu \mathrm{g} / \mathrm{ml}$; Roche), and stained with rabbit anti-PlxnA2 antibodies (Suto et al., 2007). 3T3 cells were cultured with DMEM (Sigma) containing 10\% fetal bovine serum (JRH Biosciences).

Neurite outgrowth assay. Explants of the dentate gyrus from P2 mouse were cultured for $3 \mathrm{~d}$ on monolayer sheets of 6B/3T3 cells, A2/3T3 cells, A2::6B/3T3 cells, or parental 3T3 cells with a medium consisted of $70 \%$ DMEM, 15\% HBSS, and 15\% fetal bovine serum supplemented with B-27 Supplement Minus AO (Invitrogen) and $25 \mathrm{~mm}$ D-glucose. On the second day, half volume of the medium was exchanged with fresh one. Some dentate explants were cultured in PLL-coated chamber slides for $2.5 \mathrm{~d}$. The cultures were fixed and immunostained with calbindin antibodies.

\section{Results}

\section{Generation of Sema6B knock-out mice}

Sema6B is expressed in developing hippocampus (see Fig. $3 A$ ). Therefore, to address functions of Sema6B, we generated Sema6B mutant mice by targeted disruption of the gene. Most parts of the exon 2, including the sequences encoding the first methionine, and the exons 3-7 of the Sema6B gene were replaced by the PGKneo-poly(A) cassette and the EGFP-poly(A) cassette (Fig. 1) (for details, see Materials and Methods). As the targeted locus lacks the initiation codon and instead contains the poly(A)- added neomycin-resistant gene and the GFP gene, Sema6B homozygous mice (Sema6B ${ }^{-1-}$ mice) were expected to be protein null. Immunoblot analysis revealed a band at $\sim 100 \mathrm{kDa}$ position in the brain extracts from E16.5 wild-type but not Sema6B-/- embryos (Fig. $1 D$ ), indicating that the mutant mice lack the intact Sema6B proteins. Homozygous animals were recovered from mating of heterozygous parents at a frequency that was predicted by the laws of Mendelian inheritance, suggesting that the deprivation of Sema6B does not affect the viability of the animals. In addition, both male and female homozygous mice were fertile.

\section{Abnormal projection of mossy fibers in Sema6B mutant mice}

We first examined projection patterns of mossy fibers in adult Sema6B mutant mice by Timm staining and calbindin immunohistochemistry, which can visualize presynaptic terminals and trajectories of mossy fibers, respectively. In Sema6B homozygous (Sema6B $\left.{ }^{-1-}\right)$ mice $(n=10)$, projection of mossy fibers was abnormal in several points. As in wild-type mice (Fig. 2A,I), mossy fibers in Sema6B mutant mice innervated into proximal parts of the suprapyramidal and infrapyramidal regions of CA3 and formed the suprapyramidal and infrapyramidal bundles, respectively (Fig. 2E,J). However, the suprapyramidal bundle was thicker and the infrapyramidal bundle was longer in Sema6B mutants than in wild-type animals (Fig. 2, compare $A, E$; also see Fig. $7 H$ ). Several Timm-positive spots were observed in SR and $\mathrm{SO}$ of CA3ab in the mutants but not wild-type animals (Fig. 2, compare $G, H, C, D)$, indicating inappropriate spreading of mossy fibers from the suprapyramidal and infrapyramidal bundles into SR and SO. In addition, several mossy fibers directly invaded SR and SO of CA3c without forming the suprapyramidal or infrapyramidal bundles (Fig. $2 F, J$ ). These results indicate that Sema6B plays roles in proper projection of mossy fibers.

It has been reported that the first mossy fibers invade CA3 at around $\mathrm{P} 0$, and their number gradually increases during postnatal development (Amaral and Dent, 1981). As Sema6B is expressed in the hippocampus of neonatal mice (see Fig. $3 A$ ), we examined whether deficiency of Sema6B induces abnormal projection of mossy fibers in early postnatal stages. Timm staining, calbindin immunohistochemistry, or dye filling of mossy fibers in P5 and P10 Sema6B ${ }^{-1-}$ mice, however, did not successfully demonstrate abnormal projection of the fibers, probably because of the small number of aberrant mossy fibers. On the other hand, cultures of hippocampal slices from P 5 Sema $6 B-/-$ mice for $5 \mathrm{~d}$ demonstrated obvious abnormality in mossy fiber projection. In the hippocampal slices from wild-type animals $(n=22)$, mossy fibers terminated exclusively at proximal parts of the suprapyramidal region to form a tightly packed suprapyramidal bundle (Fig. $2 \mathrm{~K}$ ). In contrast, in the hippocampal slices from Sema6B mutants $(n=18)$, mossy fibers formed a very thin suprapyramidal bundle and, instead, spread widely within SR (Fig. $2 L$ ). These results indicate that Sema6B is required for proper projection of mossy fibers from the beginning of its development. 

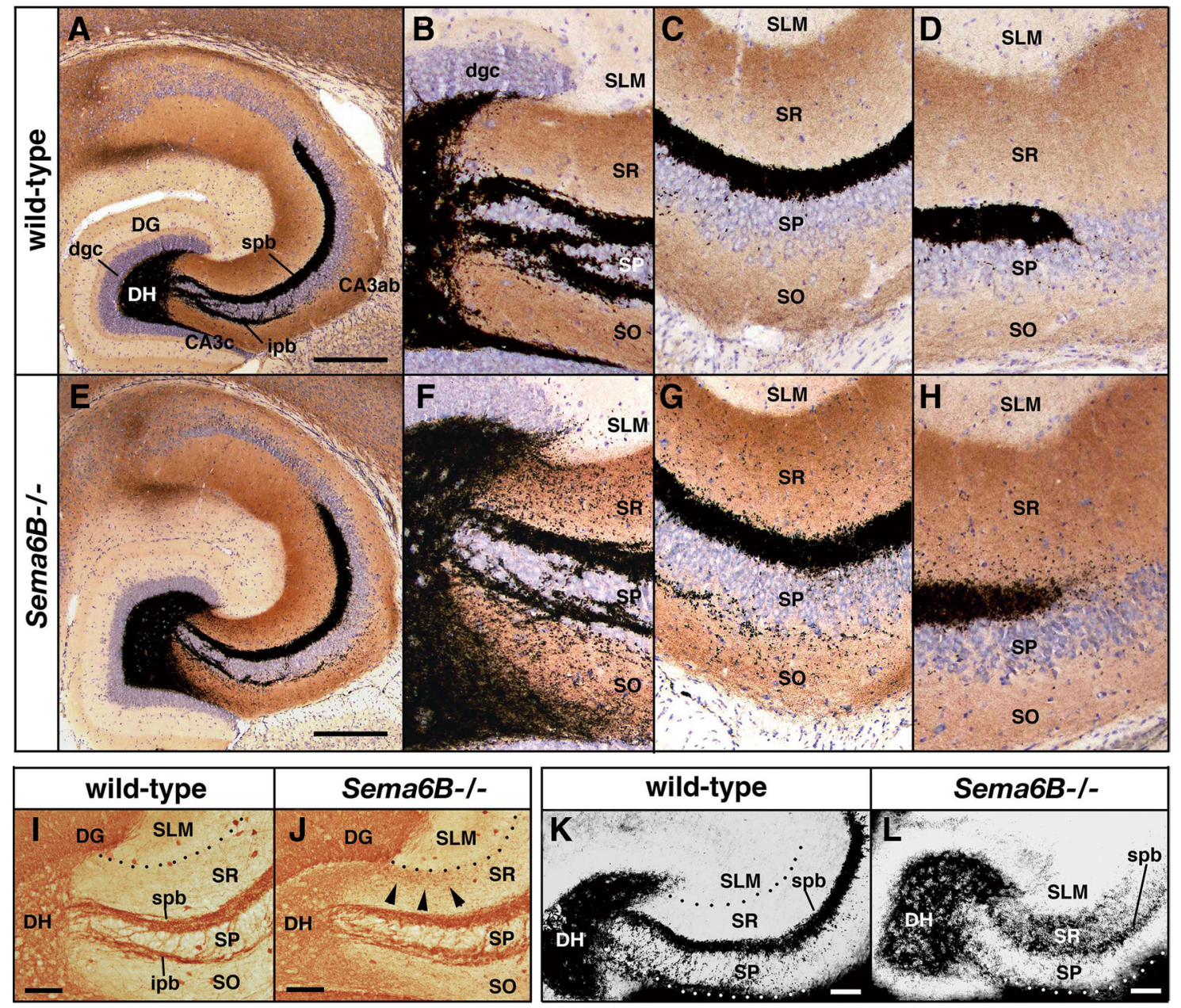

Figure 2. Mossy fiber projection in Sema6B mutant mice. $\boldsymbol{A}-\boldsymbol{J}$, Timm staining $(\boldsymbol{A}-\boldsymbol{H})$ and immunostaining with calbindin $(\boldsymbol{I}, \boldsymbol{J})$ of horizontal sections of the hippocampus of adult wild-type and Sema6B homozygous (Sema6B ${ }^{-I-}$ ) mice. The regions corresponding to CA3C, the middle part of CA3ab, and the distal-most part of CA3ab in $\boldsymbol{A}$ and $\boldsymbol{E}$ are shown at a higher magnification in $\boldsymbol{B}-\boldsymbol{D}$ and $\boldsymbol{F}-\boldsymbol{H}$, respectively. Arrowheads in $\boldsymbol{J}$ indicate mossy fibers that directly grow into the SR. DG, Dentate gyrus; DH, dentate hilus; SL, stratum lucidum; dgc, dentate granule cell; spb, suprapyramidal bundle of mossy fibers; ipb, infrapyramidal bundle of mossy fibers. These abbreviations also apply to other figures of this article. $K, L$, Timm staining of hippocampal slices from P5 wild-type and Sema6B-/- mice that were cultured for 5 d. Scale bars: $A, E, 400 \mu \mathrm{m} ; I-L, 100 \mu \mathrm{m}$.

\section{Expression of Sema6B in CA3 pyramidal cells is essential for} proper projection of mossy fibers

In situ hybridization analysis revealed that expression of Sema6B was prominent in CA3 pyramidal cells of neonatal mice in which mossy fibers are vigorously growing into CA3 (Fig. 3A). Sema6B was also expressed in dentate granule cells, raising a question as to whether Sema6B in CA3 pyramidal cells and/or dentate granule cells is essential for proper projection of mossy fibers. To address this question, we prepared slices of the dentate gyrus and CA3 from P5 wild-type and Sema6B $B^{-1-}$ mice, cocultured them in various combinations (Fig. $3 B$ ) for $5 \mathrm{~d}$, and then examined projection patterns of mossy fibers.

In cocultures of CA3 slices from wild-type mice with dentate gyrus slices from wild-type mice $(n=18)$ (Fig. $3 C)$ or Sema6B ${ }^{-1-}$ mice $(n=20)$ (Fig. $3 E)$, mossy fibers projected to proximal-most parts of the suprapyramidal region of CA3, the normal projection sites for the fibers. In contrast, when CA3 slices from Sema6B-/- mice were cocultured with dentate gyrus slices from wild-type mice $(n=19)$ (Fig. $3 D)$ or Sema6 $B^{-l-}$ mice $(n=23)$ (Fig. $3 F$ ), mossy fibers abnormally spread into SR, as observed in the hippocampal slices from Sema6B-/- mice (see Fig. $2 L$ ). These results indicate that Sema6B in CA3 pyramidal cells plays a primal role in proper projection of mossy fibers.
We next addressed the question of the subcellular localization of Sema6B proteins in pyramidal cells. All Sema6B antibodies tested were not usable for immunohistochemistry. We therefore transfected cultured hippocampal neurons with an expression plasmid for myc-tagged full-length Sema6B and found that the exogenous Sema6B proteins were localized on dendrite-like but not axon-like cell processes (supplemental Fig. 1, available at www.jneurosci.org as supplemental material). The result suggests that the Sema6B proteins exist on dendrites of pyramidal cells in vivo.

\section{Sema6B is a repellent for mossy fibers}

The abnormal innervation of mossy fibers into SR and SO in Sema6B-deficient mice raises a possibility that Sema6B functions as a repellent for mossy fibers to prohibit innervation of the fibers into the laminae. To test the possibility, we investigated whether Sema6B can collapse growth cones of mossy fibers. Figure 4, A and $C$, shows that recombinant proteins for the Fc-dimerized Sema6B ectodomain Sema6Bect-Fc collapsed growth cones of mossy fibers from wild-type animals in a dose-dependent manner. In contrast, the recombinant proteins did not collapse growth cones of mossy fibers from PlxnA4 homozygous $\left(P l x n A 4^{-1-}\right)$ mice (Fig. 4B,C). 

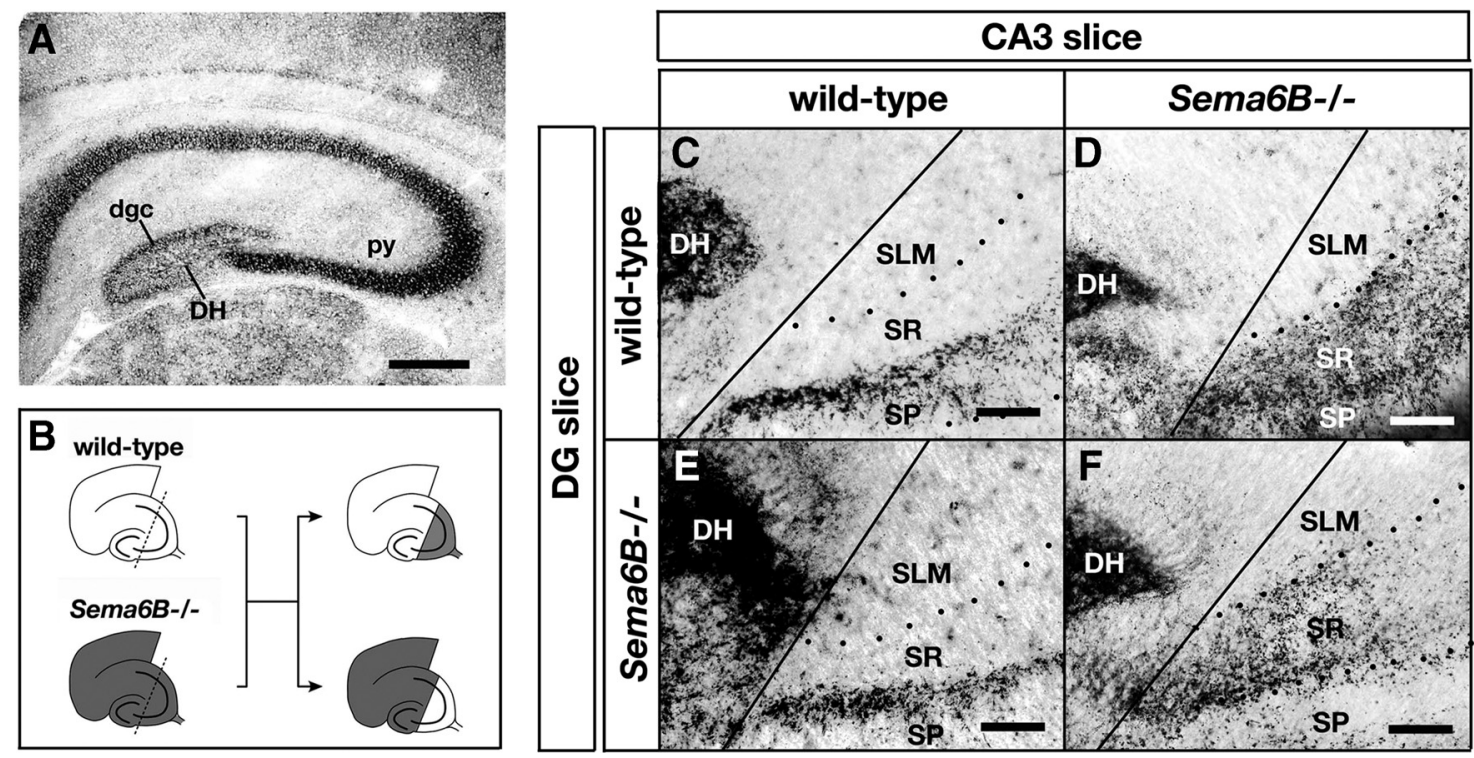

Figure 3. Expression of Sema6B and mossy fiber projection in chimeric cocultures of hippocampal slices. $A$, Expression of Sema6B in the hippocampus of P5 mice detected by ISH analysis. Note a strong ISH signal in pyramidal cells (py). $\boldsymbol{B}$, Schematic diagram of the chimeric coculture. Horizontal slices of the hippocampus of P5 wild-type and Sema6B ${ }^{-1-}$ mice are divided into two pieces; a slice that contains the dentate gyrus (DG slice) and a slice that contains $C A 3$ (CA3 slice). The DG slices and the CA3 slices were combined in various combinations and cultured for $5 \mathrm{~d}$. $C-F$, Timm staining of the cocultures. Solid lines indicate the border of the DG slice and CA3 slice. Dotted lines indicate the boundary between SLM and SR in C $\boldsymbol{F}$ and also SR and SP in $\boldsymbol{F}$. Scale bars: $\boldsymbol{A}, 200 \mu \mathrm{m}$; $C-F, 100 \mu \mathrm{m}$

We further investigated whether Sema6B suppresses growth of mossy fibers. We cultured explants of the dentate gyrus from P2 mice on monolayer sheets of NIH3T3 cells (3T3 cells) or 3T3 cells that stably expressed the full-length mouse Sema6B proteins (6B/3T3 cells). Outgrowth of mossy fibers from wild-type dentate explants vigorously occurred on 3T3 cells (Fig. 4D) but was suppressed on $6 \mathrm{~B} / 3 \mathrm{~T} 3$ cells (Fig. $4 F$ ); average length of mossy fibers on $6 \mathrm{~B} / 3 \mathrm{~T} 3$ cells was $104 \pm 3 \mu \mathrm{m}$ and was less than onethird of that on $3 \mathrm{~T} 3$ cells $(378 \pm 11 \mu \mathrm{m})$ (Fig. $4 H)$. In contrast, mossy fibers from PlxnA4-deficient dentate explants sprouted well on both 3T3 cells and 6B/3T3 cells (Fig. 4E,G,H).

Taken collectively, the results obtained by the growth cone collapse assay and the neurite outgrowth assay indicate that Sema6B functions as a repellent for mossy fibers and, furthermore, that the repulsive activity of the semaphorin is mediated by PlxnA4.

\section{Sema6A and Sema6B additively suppress aberrant projection of mossy fibers}

Our previous study has shown that Sema6A mutant mice do not show any obvious abnormality in mossy fiber projection, although Sema6A functions as a potent repellent for mossy fibers in vitro (Suto et al., 2007), raising a possibility that activities of Sema6A are compensated by Sema6B. We therefore examined projection patterns of mossy fibers in Sema6A;Sema6B double knock-out mice. In Sema6A;Sema6B double homozygous mice $\left(\right.$ Sema6 $A^{-/-}$;Sema6B-/- mice; $n=8$ ), the suprapyramidal bundle was thicker and the infrapyramidal bundle was longer than in Sema6B mutant mice (compare Figs. 5A-D, 2E-H). More mossy fibers aberrantly spread into SR and SO of CA3ab in the Sema6A;Sema6B double mutants than in Sema6B mutants (compare Figs. $5 C, D, 2 G, H$ ). In addition, number of mossy fibers that directly grew into SR and SO of CA3c increased in the double mutants (Fig. 5B). These results indicate that not only Sema6B but also Sema6A function as mossy fiber repellents to suppress aberrant spreading of mossy fibers into SR and SO.
Repulsive activities of both Sema6A and Sema6B are mediated by PlxnA4. Therefore, we had initially expected that projection patterns of mossy fibers in Sema6A;Sema6B double mutants would be closely related to those in PlxnA4 mutants. Mossy fiber phenotypes, however, were different between these two mutant mouse lines; mossy fibers aberrantly spread into SR and SO, but not SLM, in Sema6A;Sema6B double mutants, but into SR, SO, and SLM in PlxnA4 mutants (Suto et al., 2007) (Fig. 5E). These findings suggest the existence of additional PlxnA4-related mossy fiber repellent(s) in SLM.

We noted an additional defect in the projection of mossy fibers in these mutants. Mossy fibers do not normally invade the molecular layer of the dentate gyrus (Fig. $5 F$ ). In Sema6B mutants, however, a few Timm-positive spots were detected in the inner third of the molecular layer, the inner molecular layer, which is a target lamina for axons of mossy cells located in the dentate hilus (Fig. 5G). Aberrant projection of mossy fibers to the inner molecular layer was more prominent in Sema6A;Sema6B double mutants than in Sema6B mutants (Fig. 5, compare $H, G$ ), although mossy fibers did not ectopically project to the molecular layer in Sema6A single mutants (data not shown). On the other hand, in PlxnA4 mutants several Timm-positive spots were detected not only in the inner molecular layer but also the outer molecular layer that normally receives fibers from the entorhinal cortex (Fig. 5I). These results indicate that Sema6A and Sema6B also serve as repellents for mossy fibers in the dentate gyrus to prevent abnormal projection of the fibers into the molecular layer and, furthermore, that the outer molecular layer contains other PlxnA4-related repellent(s) for mossy fibers.

ISH signals for the PlxnA4 transcripts were detected in cells of the dentate hilus, and the PlxnA4 proteins were observed in the inner molecular layer (Suto et al., 2007) (supplemental Fig. 2, available at www.jneurosci.org as supplemental material), suggesting that mossy cells express PlxnA4. We therefore examined projection patterns of mossy cell axons in the mutant mice by immunohistochemistry with antibodies against calretinin, a 
marker for mossy cells (Fig. 5J). In Sema6A and Sema6B mutants, calretininpositive mossy cell axons slightly spread into the outer molecular layer, the incorrect target lamina for these axons (supplemental Fig. 3, available at www.jneurosci. org as supplemental material). Ectopic spreading of mossy cell axons into the outer molecular layer was prominent in Sema 6 ; Sema $6 B$ double mutants, though the majority of mossy cell axons remained at their normal target sites to form a discrete lamina, the inner molecular layer (Fig. 5K). In contrast, in PlxnA4 mutants most mossy cell axons spread into the outer molecular layer and, thereby, the original inner molecular layer completely disappeared (Fig. 5L). These results indicate that Sema6A, Sema6B, and unknown PlxnA4-related repellent(s) in the outer molecular layer also play roles in lamina-restricted projection of mossy cell axons.

PlxnA2 does not attenuate the repulsive activity of Sema6B but itself promotes growth of mossy fibers

We have previously shown that Sema6A binds to both PlxnA2 and PlxnA4 with approximately equal affinity and proposed that PlxnA2 would competitively suppress binding of Sema6A to PlxnA4 and thereby attenuate the Sema6A response on mossy fibers (Suto et al., 2007). As Sema6B also binds to PlxnA2 (Toyofuku et al., 2008), we tested whether PlxnA2 can attenuate the Sema6B response by using the growth cone collapse assay and the neurite outgrowth assay.

To examine the effects of PlxnA2 on the growth cone collapse activity of Sema6B, recombinant proteins for Sema6B (Sema6BectFc) or Sema6A (Sema6Aect-Fc) were first incubated with Fc-dimerized recombinant proteins for the sema domain of PlxnA2 (PlxnA2SD-Fc) or the human alkaline phosphatase (AP-Fc) for $30 \mathrm{~min}$ and then added to the explant cultures of the dentate gyrus (for details, see Materials and Methods). Preincubation of Sema6A with PlxnA2 sema domain significantly reduced the Sema6Ainduced growth cone collapse (Fig. 6A), confirming our previous study (Suto et al., 2007). In contrast, preincubation of Sema6B with PlxnA2 sema domain did not affect on the growth cone collapse activity of the semaphorin.

The above results suggest that PlxnA2 does not competitively suppress binding of Sema6B to PlxnA4 and thereby fails to attenuate the Sema6B response. The results, however, do not exclude a possibility that the sema domain is insufficient to evoke a strong binding of Sema6B to PlxnA2. Therefore, we examined whether Sema6B binds to the full-length PlxnA2 and PlxnA4 with comparable affinities. As the $K_{\mathrm{d}}$ values for the interaction of Sema6B with PlxnA2 or PlxnA4 were not determined (Suto et al., 2005) (our unpublished observations), we performed the absorption
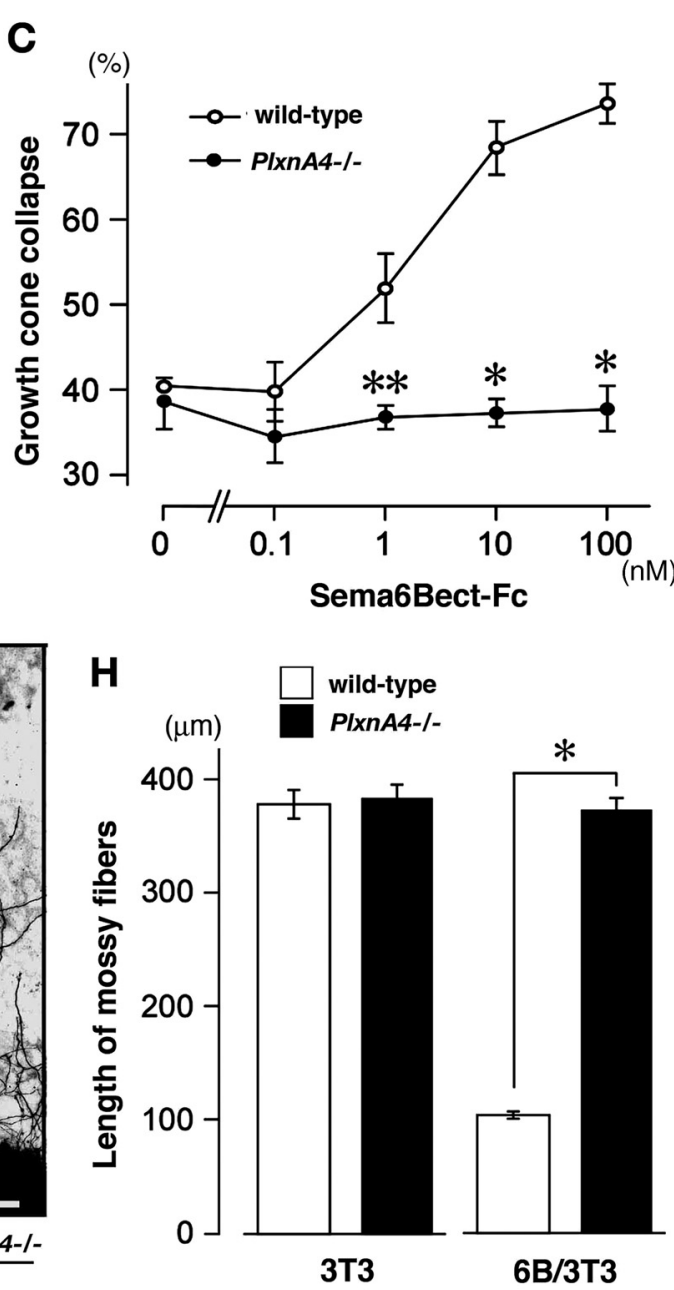

Figure 4. Effects of Sema6B on cultured mossy fibers. A-C, Collapse of growth cones by Sema6B. Explants of the dentate gyrus 政e $(\boldsymbol{D}, \boldsymbol{F})$ or PlxnA4-/- mice $(\boldsymbol{E}, \boldsymbol{G})$ were cultured on monolayer sheets of $3 T 3$ cells $(\boldsymbol{D}, \boldsymbol{E}, 3 \mathrm{~T} 3)$ or Sema6Bexpressing $3 \mathrm{~T} 3$ cells $(\boldsymbol{F}, \boldsymbol{G}, 6 \mathrm{~B} / 3 \mathrm{~T} 3)$ for $3 \mathrm{~d}$ and stained with calbindin antibodies. The average length of mossy fibers is given in $\boldsymbol{H}$. e average length for the longest two mossy fibers for each dentate explant was designated as the length of mossy fibers for the given explant. The length of mossy fibers was determined for $>10$ explants for each mouse (from five littermates). Vertical bars indicate SEM; ${ }^{*} p<0.001 ;{ }^{* *} p<0.005$ (Student's $t$ test). Scale bars: $A, B, 10 \mu \mathrm{m} ; \mathbf{D}-\mathbf{G}, 50 \mu \mathrm{m}$.

test. Sema6Bect-Fc or Sema6Aect-Fc recombinant proteins were first absorbed with $\mathrm{L}$ cells that expressed full-length PlxnA2 (LA2 cells) or PlxnA4 (LA4 cells), and then their growth cone collapse activities were examined (for details, see Materials and Methods). Preabsorption of Sema6A with either LA2 cells or LA4 cells significantly reduced the growth cone collapse activity of Sema6A (Fig. 6B). On the other hand, preabsorption of Sema6B with LA2 cells did not affect the growth cone collapse activity of Sema6B, although preabsorption with LA4 cells significantly reduced the Sema6B response. These results suggest that the affinity between PlxnA2 and Sema6B is too low to interfere with the PlxnA4-mediated growth cone collapse activity of Sema6B.

We further examined whether PlxnA2 interferes with the Sema6B-induced suppression of mossy fiber outgrowth. We cultured explants of the dentate gyrus on monolayer sheets of $6 \mathrm{~B} /$ 

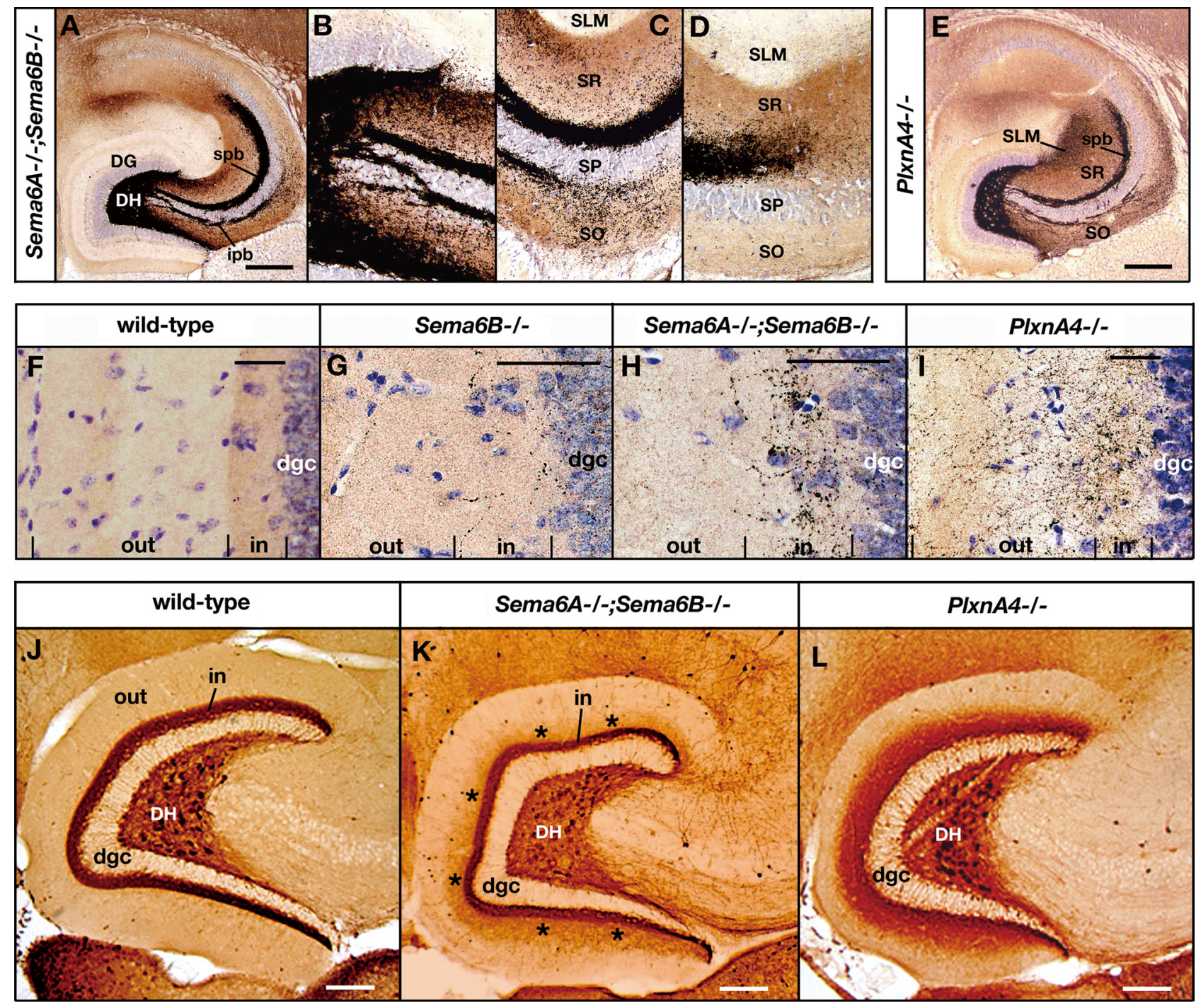

Figure 5. Abnormal projection of mossy fibers and mossy cell axons in Sema6A;Sema6B double knock-out mice and P/xnA4 mutant mice. $\boldsymbol{A}-\boldsymbol{D}$, Timm staining of a horizontal section of the hippocampus of an adult Sema6A ${ }^{-1-}$;Sema6B-/- mouse. The regions corresponding to CA3C, the middle part of CA3ab, and the distal-most part of CA3ab in $\boldsymbol{A}$ are shown at a higher magnification in $\boldsymbol{B}-\boldsymbol{D}$. E, Timm staining of a horizontal section of the hippocampus of an adult PlxnA4 ${ }^{-1-}$ mouse. $\boldsymbol{F}-\boldsymbol{I}$, Timm staining of horizontal sections of the dentate molecular layer of adult wild-type and mutant mice. out, Outer molecular layer; in, inner molecular layer. $J-L$, Calretinin immunohistochemistry of horizontal sections of the dentate gyrus of adult wild-type and mutant mice. Note that calretinin-positive mossy cell axons spread ectopically into the outer molecular layer in Sema6A;Sema6B double mutants ( $\boldsymbol{K}$, asterisks) and P/xnA4 mutants ( $\boldsymbol{L}$ ). Scale bars: $\boldsymbol{A}, \boldsymbol{E}, 400$ $\mu \mathrm{m} ; \boldsymbol{F}-\mathbf{I}, 50 \mu \mathrm{m} ; J-L, 200 \mu \mathrm{m}$.

$3 \mathrm{~T} 3$ cells or A2::6B/3T3 cells in which the full-length PlxnA2 was coexpressed with Sema6B. To our surprise, the coexpression of PlxnA2 with Sema6B mitigated the Sema6B-induced suppression of mossy fiber outgrowth (Fig. 6C). Furthermore, mossy fibers grew longer on PlxnA2-expressing A2/3T3 cells than parental $3 \mathrm{~T} 3$ cells. Addition of recombinant proteins for the PlxnA2 sema domain to the dentate explant cultures also enhanced outgrowth of mossy fibers on 3T3 cells, 6B3T3 cells, and PLL-coated culture plates (Fig. 6D). These results indicate that PlxnA2 itself promotes growth of mossy fibers.

Roles of Sema6A, Sema6B, and PlxnA2 in the formation of the suprapyramidal bundle

To evaluate further functions of Sema6A, Sema6B, and PlxnA2 in lamina-restricted projection of mossy fibers, we compared the thickness of the suprapyramidal bundle among Sema6A, Sema6B, and PlxnA2 mutant mice and double knock-out mice for these genes.
We first describe projection patterns of mossy fibers in PlxnA2;Sema6B double knock-out mice. As reported previously (Suto et al., 2007), Figure $7 G$ shows that mossy fibers in PlxnA2 homozygous $\left(P l x n A 2^{-l-}\right)$ mice terminated at proximal parts of the infrapyramidal region and stratum pyramidalis (SP), but never innervated into the suprapyramidal region. In contrast, in PlxnA2;Sema6B double homozygous mice (PlxnA2-/-; Sema $6 B^{-1-}$ mice; $n=6$ ), mossy fibers initially grew into proximal parts of the infrapyramidal region and SP of CA3c, but eventually invaded proximal parts of the suprapyramidal region of CA3ab to form the suprapyramidal bundle (Fig. $7 A-D$ ). The suprapyramidal bundle, however, was thinner than that of wildtype animals (compare Figs. 7A, 2A) (Fig. 7H). Furthermore, spreading of mossy fibers from the suprapyramidal and infrapyramidal bundles into SR or SO of CA3ab, which is a typical phenotype in Sema6B mutants, did not occur in the PlxnA2;Sema6B double mutants (Fig. 7C,D), although some mossy fibers directly invaded SR and SO of CA3c (Fig. 7B). In PlxnA2;Sema6B double 
mutants, mossy fibers sometimes grew into SP of CA1 (Fig. 7A). Projection patterns of mossy fibers in PlxnA2-/-; Sema $6 B^{+/-}$mice $(n=5)$ were closely related to those in PlxnA2-/- mutant mice; mossy fibers were restricted to proximal parts of the infrapyramidal region and SP in most parts of CA3, except distal parts of CA3ab, where some mossy fibers grew into the suprapyramidal region and formed a very thin suprapyramidal bundle (Fig. $7 F$ ). Projection patterns of mossy fibers in PlxnA2 $2^{+/-}$;Sema6B-/mice $(n=5)$ were similar to those in Sema $6 B^{-1-}$ mice (data not shown). The results suggest that Sema6B suppresses innervation of mossy fibers into the suprapyramidal region, depending on the dosage of the Sema6B gene.

Next, to quantify projection areas for mossy fibers in the suprapyramidal region, we measured the thickness of the suprapyramidal bundle within CA3ab at the position $350 \mu \mathrm{m}$ from the CA3-CA1 boundary in the semaphorin and plexin mutant mouse lines. We have previously reported that projection of mossy fibers is mostly normal in Sema6A mutants and PlxnA2;Sema6A double mutants (Suto et al., 2007). The present numerical analysis revealed that the thickness of the suprapyramidal bundles was not significantly different between Sema6A mutants and wild-type animals. The suprapyramidal bundle of PlxnA2;Sema6A double mutants, however, was slightly thinner than that of wild-type animals $(p<0.01)$. The suprapyramidal bundle of PlxnA2;Sema6B double mutants was thinner than that of wild-type animals $(p<0.005)$ and also PlxnA2; Sema6A double mutants $(p<0.01)$, indicating that, in the absence of PlxnA2, Sema6A is a more potent repellent for mossy fibers than Sema6B to suppress innervation of the fibers into the suprapyramidal region. On the other hand, the suprapyramidal bundle of Sema6B mutants was significantly thicker than that of Sema6A mutants $(p<0.001)$ and wild-type animals $(p<0.001)$. These results suggest that mossy fiber repulsion by Sema6A but not Sema6B is attenuated by PlxnA2, resulting in the aberrant spreading of mossy fibers in Sema6B but not Sema6A mutants. Thickness of the suprapyramidal bundle of Sema6A;Sema6B double mutants was not exactly determined because of vigorous sprouting of mossy fibers into SR (Fig. 5C,D). However, it is obvious that the suprapyramidal bundle of the double mutants is thicker than that of Sema6B mutants.

\section{Discussion}

Sema6A, Sema6B, and other PlxnA4-related repellent(s) regulate proper projection of mossy fibers

This study has shown that Sema6B, a member of class 6 semaphorin, collapses growth cones in PlxnA4-expressing mossy fibers and suppresses outgrowth of the fibers in vitro and,
B

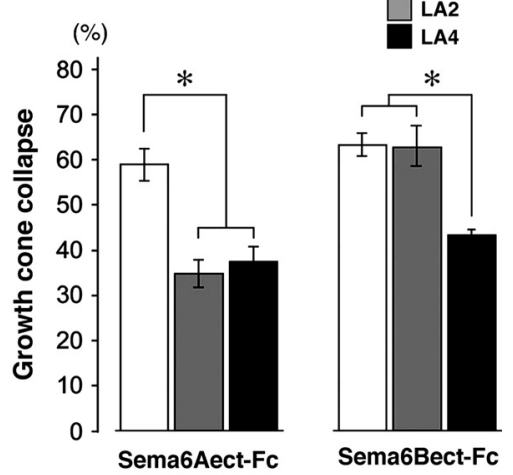

D

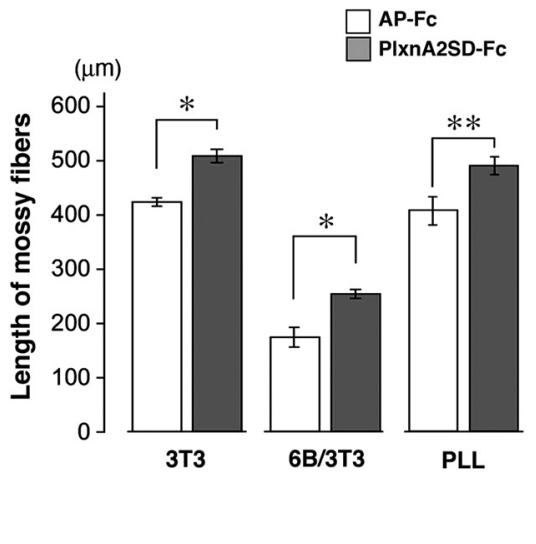

Figure 6. Effects of PlxnA2 on the Sema6B response. A, Effects of PlxnA2 sema domain on Sema6A-induced and Sema6Breincubated with PlxnA2 sema domain (PlxnA2SD-Fc) or alkaline phosphatase (AP-Fc) (see Materials and Methods) and then the explant cultures of the dentate gyrus from P2 mice. $B$, Effects of PlxnA2 on Sema6A-induced and Sema6B-induced PlxnA2-expressing LCells (LA2), or PlxnA4-expressing Lcells (LA4) and then applied to the cultures. In $A, B$ the average percentages in growth cone collapse were calculated for five independent experiments. $C$, Effects of PlxnA2 on mossy fiber outgrowth. Explants of the dentate gyrus from P2 wild-type mice were cultured on monolayer sheets of $3 T 3$ cells, Sema6B-expressing cells (6B/3T3 ells), PlxnA2-expressing cells (A2/3T3), or cells that coexpress PlxnA2 and Sema6B (A2::6B/3T3). Data for the explant culture on of the dentate gyrus were cultured on monolayer sheets of $3 \mathrm{~T} 3$ cells, $6 \mathrm{~B} / 3 \mathrm{~T} 3$ cells, or PLL-coated culture plates under the presence of PlxnA2SD-Fc (100 nM) or AP- $\mathrm{Fc}(100 \mathrm{~nm})$. The average length of mossy fibers was calculated for five independent experiments. Vertical bars indicate SEM; ${ }^{*} p<0.001,{ }^{* *} p<0.01$ (Student's $t$ test).

furthermore, that Sema6B deficiency in mice induces spreading of mossy fibers into incorrect target laminae within CA3. These results indicate that Sema6B signals via PlxnA4 function as repellents for mossy fibers (Fig. 8A) and play crucial roles in proper projection of the fibers.

We have previously shown that signals of Sema6A, another member of class 6 semaphorin, are also mediated by PlxnA4 and repel mossy fibers (Suto et al., 2007) (Fig. 8A). The Sema6A response, however, is attenuated by PlxnA2 (Suto et al., 2007) (Fig. $8 A$ ), and therefore Sema6A-deficient mice do not show any abnormality in mossy fiber projection (Suto et al., 2007). The lack of mossy fiber phenotype in Sema6A mutants has raised a question for the function of Sema6A in mossy fiber projection. This study has revealed that more aberrant mossy fibers are induced in Sema6A;Sema6B double mutants than in Sema6B mutants (Fig. $8 B$ ) and, furthermore, that PlxnA2;Sema6B double mutants in which PlxnA2 is deprived, thereby allowing the repulsive activi- 

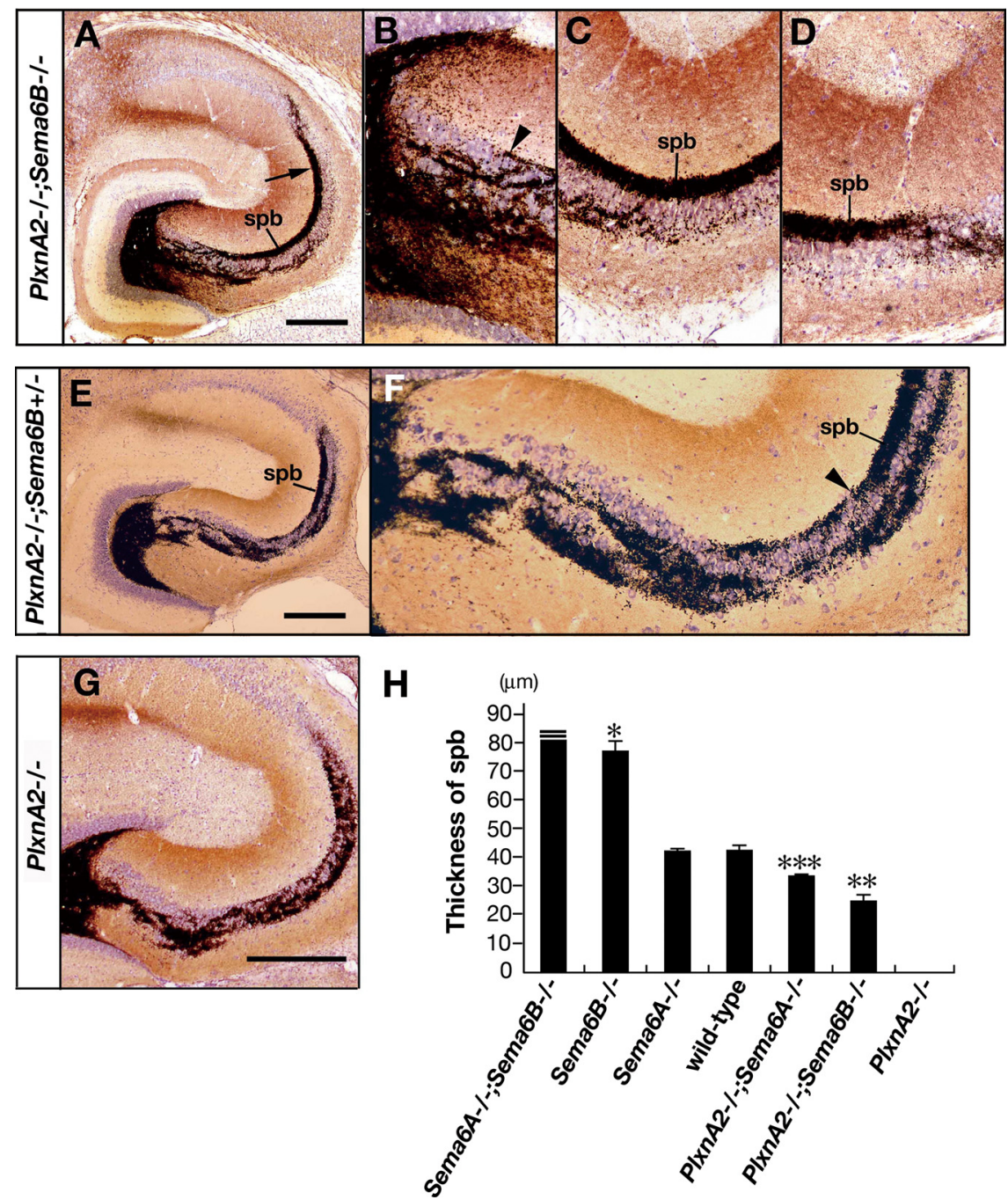

Figure 7. Formation of the suprapyramidal bundle (spb) in semaphorin and plexin mutant mice. $\mathbf{A}-\mathbf{G}$, Timm staining of

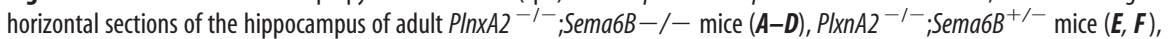
and $P / x n A 2^{-1-}$ mice $(G)$. The regions corresponding to $C A 3 c$, the middle part of $C A 3 a b$, and the distal-most part of $C A 3 a b$ in $A$ and $\boldsymbol{E}$ are shown at a higher magnification in $\boldsymbol{B}-\boldsymbol{D}$ and $\boldsymbol{F}$, respectively. Arrowheads in $\boldsymbol{B}$ and $\boldsymbol{F}$ indicate the positions where mossy fibers first innervated into the suprapyramidal region to form the suprapyramidal bundle. $\boldsymbol{H}$, Thickness of the spb in adult mice. Thickness of the suprapyramidal bundle was determined within CA3ab at the position $350 \mu \mathrm{m}$ from the CA3-CA1 boundary ( $A$, arrow), for $>15$ horizontal sections of each mouse (from five mice for each line). PlxnA2 mutant mice lack the suprapyramidal bundle. Vertical bars indicate SEM; ${ }^{*} p<0.001,{ }^{* *} p<0.005$, and ${ }^{* * *} p<0.01$ against wild-type mice (Student's $t$ test). Scale bars: $A, E, G, 400 \mu \mathrm{m}$.

ties of Sema6A to remain intact, exhibit a significant reduction in mossy fiber innervation into the suprapyramidal region (Fig. $8 B)$. We therefore conclude that repulsive activities of Sema6A also play a practical role in proper projection of mossy fibers. The PlxnA2 proteins are distributed in a proximodistal gradient within the suprapyramidal region (Suto et al., 2007). Therefore, the Sema6A response would be completely attenuated in proximal-most parts of the suprapyramidal region, resulting in a mossy fiber phenotype in wild-type animals similar to that in Sema6A mutants. On the other hand, in distal parts of the suprapyramidal region the Sema6A response would be suppressed but not attenuated completely by PlxnA2. This may cause the wider spreading of mossy fibers in Sema6A;Sema6B double mutants than in Sema6B mutants.

This study has shown that the abnormal projection of mossy fibers in Sema6B mutants is due to the deficiency of Sema6B in CA3 pyramidal cells but not mossy fibers. The present transfec- tion study suggests that Sema6B exists on dendrites of pyramidal cells and prevents innervation of mossy fibers into the suprapyramidal and infrapyramidal regions where pyramidal cell dendrites are distributed. The transfection study, however, cannot completely rule out the possibility that Sema6B exists on axons of pyramidal cell. Sema6A exists on both dendrites and axons of pyramidal cells (Suto et al., 2007). Kapfhammer and Raper (1987a,b) have reported repulsive interaction between different fiber classes. Therefore, it is also possible that axons of pyramidal cells in SR and SO, the commissural/associational fibers, contain Sema6A and Sema6B and repel PlxnA4-expressing mossy fibers to prevent their innervation into SR and SO. Whatever the subcellular localization of Sema6A and Sema6B, these two repellents play primary roles in proper projection of mossy fibers in CA3.

Many studies have addressed cellular and molecular mechanisms governing laminated afferent projection in the dentate molecular layer (for a review, see Förster et al., 2006). However, less attention has been paid to the mechanisms that prevent mossy fibers from growing into the molecular layer. This study has demonstrated that Sema6A and Sema6B are required to prevent abnormal innervation of mossy fibers into the molecular layer. Furthermore, this study has shown that Sema6A and Sema6B suppress ectopic spreading of PlxnA4-expressing mossy cell axons to detain them at their correct target lamina. These findings indicate that PlxnA4-mediated repulsive signals of Sema6A and Sema6B also play crucial roles in neuronal circuit assembly in the dentate gyrus.

This study has shown that, in addition to Sema6A and Sema6B, other PlxnA4related repellent(s) exist in SLM of CA3 and the outer molecular layer of the dentate gyrus to control proper projection of mossy fibers and mossy cell axons. It has been reported that cells of the entorhinal cortex secrete a diffusible repellent for mossy fibers in vitro (Chédotal et al., 1998). Therefore, entorhinal fibers in SLM and the outer molecular layer might themselves contain common PlxnA4-related repellent(s) to suppress aberrant projection of mossy fibers and mossy cell axons.

\section{Attraction of mossy fibers by PlxnA2 and unknown factor(s) in CA3}

Why can mossy fibers normally innervate into CA3, where potent mossy fiber repellents, Sema6A and Sema6B, are expressed? As discussed above, repulsive activities of Sema6A are attenuated by PlxnA2 in proximal parts but not distal parts of the suprapyramidal region. Furthermore, this study has revealed that the Sema6B response on mossy fibers is not attenuated by PlxnA2. Therefore, attractive guidance mechanisms that compensate for 
the semaphorin-induced mossy fiber repulsion and promote innervation of mossy fibers into CA3 would be required. This study has shown that PlxnA2 itself promotes outgrowth of mossy fibers in vitro (Fig. $8 A$ ). The suprapyramidal bundle is slightly thicker in Sema6A mutants than in PlxnA2;Sema6A double mutants (Fig. $8 B$ ), suggesting that the growthpromoting activity of PlxnA2 plays a practical role in the attraction of mossy fibers.

$\mathrm{PlxnA} 2$ propagates repulsive signals of class 3 semaphorins by forming receptor complexes with neuropilins (Takahashi et al., 1999). PlxnA2 also serves as a direct receptor for Sema6A and/or Sema6B in embryonic spinal motor neurons (Bron et al., 2007), developing cerebellar granule cells (Renaud et al., 2008), and cardiac neural crest cells (Toyofuku et al., 2008 ) to regulate migration and positioning of these cells. In contrast, in developing hippocampus PlxnA2 does not function as a receptor for repellents, but rather works as a neuronal attractant. It is an open question how PlxnA2 promotes growth of mossy fibers. It has been shown that plexin-A1 (Ohta et al., 1995) and plexin-B3 (Hartwig et al., 2005) induce cell adhesion by homophilical interaction and, furthermore, that the homophilical interaction of plexin-B3 enhances neurite outgrowth of cerebellar neurons (Hartwig et al., 2005). Therefore, one possibility is that PlxnA2 promotes outgrowth of mossy fibers via its trans-homophilic interaction. It has been shown that plexin-A 1 functions as not only a receptor but also as a ligand for Sema6D in cardiac morphogenesis (Toyofuku et al., 2004). Therefore, the alternative is that growth-promoting activities of $\mathrm{PlxnA} 2$ would be mediated via receptor(s) in mossy fibers. Identification of binding partners for PlxnA2 is required to understand further functions of PlxnA2 in mossy fiber projection.

In PlxnA2;Sema6A and PlxnA2;Sema6B double mutants, in which PlxnA2 is deprived while Sema6A or Sema6B remain intact, many mossy fibers innervate into proximal parts of the suprapyramidal region (Fig. $8 \mathrm{~B}$ ). These results indicate that other mossy fiber attractant(s) exist in proximal parts of the suprapyramidal region. We refer to the attractant as pan-mossy fiber attractant, PMFA (Fig. $8 \mathrm{~A}$ ). It has been reported that netrin-1 is expressed in pyramidal cells and can attract mossy fibers in vitro (Steup et al., 2000). A more recent study has shown that functional blocking of netrin-1 by specific antibodies results in the attenuation of mossy fiber growth toward CA3 in slice cultures (Muramatsu et al., 2010). Therefore, netrin-1 is a most likely candidate for PMFA. Similarly to mossy fibers in PlxnA2 mutant mice, mossy fibers in mice deficient for the neural cell adhesion molecule (NCAM) (Cremer et al., 1997) and the transcription factor serum response factor (SRF) (Knöll et al., 2006) do not

B

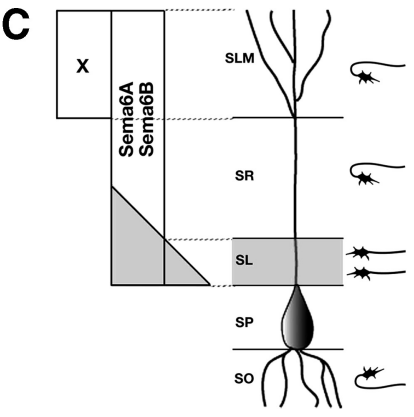

Figure 8. Summary of functions of repellents and attractants in laminar projection of mossy fibers. A, Repulsive and attractive signals that regulate mossy fibers projection. PlxnA4 is expressed in mossy fibers and serves as a receptor for two neuronal ( fiber repulsion. On the other hand, PIxnA2 itself and unknown molecule(s) in CA3 (PMFA; see Discussion) function as attractants for mossy fibers. Receptors that mediate attractive signals of PlxnA2 and PMFA have not been determined (see Discussion). $B$, Schematic diagrams of the mossy fiber projection patterns in the suprapyramidal region of CA3ab in wild-type mice, Sema6A, Sema6B, and PIxnA2 mutant mice, and double knock-out mice for these genes. The area to which mossy fibers project is repre政 pellent, $X$, in SLM is omitted. Repulsive activities of Sema6A would remain intact in P/xnA2-deficent mouse lines: PlxnA2 ${ }^{-1-}$ mice. On the other hand, Sema6A activities would be completely attenuated by PlxnA2 in wild$\nabla$ Sema6A. C, A model for the laminar projection of mossy fibers. The model shows that the relative strength of mossy fiber repulsion by Sema6A and Sema6B and attraction by PlxnA2 and PMFA (represented in sum by gray color) determines the areas permissive for mossy fibers to innervate into the suprapyramidal region of CA3ab. Mossy fiber repellent, $X$, in SLM also suppresses innervation of mossy fibers into the lamina.

grow into the suprapyrimidal and infrapyramidal regions but terminate within SP. Therefore, NCAM or SRF target genes might also function as PMFA.

\section{Balance between repulsion and attraction of mossy fibers prescribes the areas permissive for mossy fibers to grow in CA3}

On the basis of above discussion, we propose a model showing how mossy fiber repulsion by Sema6A and Sema6B and attraction by PlxnA2 and PMFA prescribe the area permissive for mossy fibers to grow in the suprapyramidal region (Fig. 8C). In the model, we assume that mossy fiber repellents, Sema6A and Sema6B, are evenly distributed throughout the suprapyramidal region. We also assume that mossy fiber attractants, PlxnA2 and PMFA, are distributed in a proximodistal gradient as a whole, although chemical nature of PMFA has been unknown. The model shows that the target lamina for mossy fibers in the supra- 
pyramidal region is not based on absolute levels of single molecules but is determined by relative balance of mossy fiber repulsion and attraction; mossy fibers innervate the areas where attractive forces overwhelm repulsive forces. In Sema6A;Sema6B double mutants that lack repellents, mossy fibers spread throughout the area where mossy fiber attractants are distributing (Fig. $8 B$ ). In PlxnA2 mutants, repulsive forces by Sema6A and Sema6B overwhelm attractive force by PMFA, and therefore mossy fibers are prevented from innervating the suprapyramidal region (Fig. $8 \mathrm{~B})$. Discrete target selection of motor axons in Drosophila is conducted by this general principle of axon guidance, with antagonistic guidance signals being produced from the same region (Winberg et al., 1998).

The above model does not explain why mossy fibers directly innervate into $S R$ in Sema6B-deficient mouse lines (Figs. $2 F, 7 B$ ) and why the fibers innervate into the infrapyramidal region of $\mathrm{CA} 3 \mathrm{c}$ in all mutant mouse lines examined. Additional attractants for mossy fibers or factors that compensate the Sema6A- and Sema6B-induced mossy fiber repulsion might exist in $\mathrm{CA} 3 \mathrm{c}$.

\section{References}

Amaral DG, Dent JA (1981) Development of the mossy fibers of the dentate gyrus: I. A light and electron microscopic study of the mossy fibers and their expansions. J Comp Neurol 191:51-86.

Amaral DG, Witter MP (1995) Hippocampal formation. In: The rat nervous system (Paxinos G, ed), pp 443-493. New York: Academic.

Bagri A, Cheng HJ, Yaron A, Pleasure SJ, Tessier-Lavigne M (2003) Stereotyped pruning of long hippocampal axon branches triggered by retraction inducers of the semaphorin family. Cell 113:285-299.

Barallobre MJ, del Río JA, Alcántara S, Borrell V, Aguado F, Ruiz M, Carmona MA, Martín M, Fabre M, Yuste R, Tessier-Lavigne M, Soriano E (2000) Aberrant development of hippocampal circuits and altered neural activity in netrin 1-deficient mice. Development 127:4797-4810.

Borrell V, Puiadas L, Simó S, Durà D, Solé M, Cooper JA, Del Río JA, Soriano E (2007) Reelin an mDab1 regulate the development of hippocampal connections. Mol Cell Neurosci 36:158-173.

Brinks H, Conrad S, Vogt J, Oldekamp J, Sierra A, Deitinghoff L, Bechmann I, Alvarez-Bolado G, Heimrich B, Monnier PP, Mueller BK, Skutella T (2004) The repulsive guidance molecule RGMa is involved in the formation of afferent connections in the dentate gyrus. J Neurosci 24:3862-3869.

Bron R, Vermeren M, Kokot N, Andrews W, Little GE, Mitchell KJ, Cohen J (2007) Boundary cap cells constrain spinal motor neuron somal migration at motor exit points by a semaphorin-plexin mechanism. Neural Dev 2:21-39.

Chédotal A, Del Río JA, Ruiz M, He Z, Borrell V, de Castro F, Ezan F, Goodman CS, Tessier-Lavigne M, Sotelo C, Soriano E (1998) Semaphorins III and IV repel hippocampal axons via two distinct receptors. Development 125:4313-4323.

Cheng HJ, Bagri A, Yaron A, Stein E, Pleasure SJ, Tessier-Lavigne M (2001) Plexin-A3 mediates semaphorin signaling and regulates the development of hippocampal axonal projections. Neuron 32:249-263.

Cremer H, Chazal G, Goridis C, Represa A (1997) NCAM is essential for axonal growth and fasciculation in the hippocampus. Mol Cell Neurosci 8:323-335.

Evan GI, Lewis GK, Ramsay G, Bishop JM (1985) Isolation of monoclonal antibodies specific for human c-myc proto-oncogene product. Mol Cell Biol 5:3610-3616.

Förster E, Kaltschmidt C, Deng J, Cremer H, Deller T, Frotscher M (1998) Lamina-specific cell adhesion on living slices of hippocampus. Development 125:3399-3410.

Förster E, Zhao S, Frotscher M (2006) Laminating the hippocampus. Nat Rev Neurosci 7:259-268.

Goslin K, Asmussen H, Banker G (1998) Rat hippocampal neurons in lowdensity culture. In: Culturing nerve cells (Bankerand G, Goslin K, eds), pp 339-370. Cambridge, MA: MIT.

Hartwig C, Veske A, Krejcova S, Rosenberger G, Finckh U (2005) Plexin B3 promotes neurite outgrowth, interacts homophilically, and interact with Rin. BMC Neurosci 6:53-71.
Kapfhammer JP, Raper JA (1987a) Collapse of growth cone structure on contact with specific neurites in culture. J Neurosci 7:201-212.

Kapfhammer JP, Raper JA (1987b) Interactions between growth cones and neuritis growing from different neural tissues in culture. J Neurosci 7:1595-1600.

Katoh K, Takahashi Y, Hayashi S, Kondoh H (1987) Improved mammalian vectors for high expression of G418 resistance. Cell Struct Funct 12:575-580.

Knöll B, Kretz O, Fiedler C, Alberti S, Schütz G, Frotscher M, Nordheim A (2006) Serum response factor controls neural circuit assembly in the hippocampus Nat Neurosci 9:195-204.

Leighton PA, Mitchell KJ, Goodrich LV, Lu X, Pinson K, Scherz P, Skarnes WC, Tessier-Lavigne M (2001) Defining brain wiring patterns and mechanisms through gene trapping in mice. Nature 410:174-179.

Liu XB, Low LK, Jones EG, Cheng HJ (2005) Stereotyped axon pruning via plexin signaling is associated with synaptic complex elimination in the hippocampus. J Neurosci 25:9124-9134.

Mitchell K, Pinson KI, Kelly OG, Brennan J, Zupicich J, Scherz P, Leighton PA, Goodrich LV, Lu X, Avery BJ, Tate P, Dill K, Pangilinan E, Wakenight P, Tessier-Lavigne M, Skarnes WC (2001) Functional analysis of secreted and transmembrane proteins critical to mouse development. Nat Genet 3:241-249.

Mizuhashi S, Nishiyama N, Matsuki N, Ikegaya Y (2001) Cyclic nucleotidemediated regulation of hippocampal mossy fiber development: a targetspecific guidance. J Neurosci 21:6181-6194.

Murakami Y, Suto F, Shimizu M, Shinoda T, Kameyama T, Fujisawa H (2001) Differential expression of plexin-A subfamily members in the mouse nervous system. Dev Dyn 220:246-258.

Muramatsu R, Nakahare S, Ichikawa J, Watanabe K, Matsuki N, Koyama R (2010) The ration of 'deleted in colorectal cancer' to 'uncoordinated-5A' netrin-1 receptors on the growth cone regulates mossy fibre directionality. Brain 133:60-75.

Nguyen-Ba-Charvet KT, Brose K, Marillat V, Kidd T, Goodman CS, Tessier-Lavigne M, Sotelo C, Chédotal A (1999) Slit2-mediated chemorepulsion and collapse of developing forebrain axons. Neuron 22:463-473.

Ohta K, Mizutani A, Kawakami A, Murakami Y, Kasuya Y, Takagi S, Tanaka H, Fujisawa H (1995) Plexin: a novel neuronal cell surface molecule that mediate cell adhesion via a homophilic binding mechanism in the presence of calcium ions. Neuron 14:1189-1199.

Otal R, Burgaya F, Frisén J, Soriano E, Martínez A (2006) Ephrin-A5 modulates the topographic mapping and connectivity of commissural axons in murine hippocampus. Neurosci 141:109-121.

Pozas E, Pascual M, Nguyen-Ba-Charvet KT, Guijarro P, Sotelo C, Chédotal A, Del Rio JA, Soriano E (2001) Age-dependent effects of secreted Semaphorins 3A, 3F, and 3E on developing hippocampal axons: in vitro effects and phenotype of Semaphorin $3 \mathrm{~A}(-/-)$ mice. Mol Cell Neurosci 18:26-43.

Renaud J, Kerjan G, Sumita I, Zagar Y, Georget V, Kim D, Fouquet C, Suda K, Sanbo M, Suto F, Ackerman SL, Mitchell KJ, Fujisawa H, Chédotal A (2008) Plexin-A2 and its ligand, Sema6A, control nucleus-centrosome coupling in migrating cerebellar granule cells. Nat Neurosci 11:440-449.

Shimizu M, Murakami Y, Suto F, Fujisawa H (2000) Determination of cell adhesion sites of neuropilin-1. J Cell Biol 148:1283-1294.

Skutella T, Nitsch R (2001) New molecules for hippocampal development. Trends Neurosci 24:107-1113.

Stein E, Savaskan NE, Ninnemann O, Nitsch R, Zhou R, Skutella T (1999) A role for the Eph ligand ephrin-A3 in entorhino-hippocampal axon targeting. J Neurosci 19:8885-8893.

Steup A, Ninnemann O, Savaskan NE, Nitsch R, Püschel AW, Skutella T (1999) Semaphorin D acts as a repulsive factor for entorhinal and hippocampal neurons. Eur J Neurosci 11:729-734.

Steup A, Lohrum M, Hamscho N, Savaskan NE, Ninnemann O, Nitsch R, Fujisawa H, Püschel AW, Skutella T (2000) Sema3C and netrin-1 differentially affect axon growth in the hippocampal formation. Mol Cell Neurosci 15:141-155.

Suto F, Murakami Y, Nakamura F, Goshima Y, Fujisawa H (2003) Identification and characterization of a novel mouse plexin, plexin-A4. Mech Dev 120:385-396.

Suto F, Ito K, Uemura M, Shimizu M, Shinkawa Y, Sanbo M, Shinoda T, Tsuboi M, Takashima S, Yagi T, Fujisawa H (2005) Plexin-A4 medi- 
ates axon-repulsive activities of both secreted and transmembrane semaphorins and plays roles in nerve fiber guidance. J Neurosci 25:3628-3637.

Suto F, Tsuboi H, Kamiya H, Mizuno H, Kiyama Y, Komai S, Shimizu M, Sanbo M, Yagi T, Hiromi Y, Chédotal A, Mitchell KJ, Manabe T, Fujisawa $\mathrm{H}$ (2007) Interactions between plexin-A2, plexin-A4 and semaphorin $6 \mathrm{~A}$ control lamina-restricted projection of hippocampal mossy fibers. Neuron 53:535-547.

Takahashi T, Fournier A, Nakamura F, Wang LH, Murakami Y, Kalb RG, Fujisawa H, Strittmatter SM (1999) Plexin-Neuropilin-1 complexes form functional semaphorin-3A receptors. Cell 99:59-69.

Toyofuku T, Zhang H, Kumanogoh A, Takegahara N, Suto F, Kamei J, Aoki
K, Yabuki M, Hori M, Fujisawa H, Kikutani H (2004) Dual roles of Sema6D in cardiac morphogenesis through region-specific association of its receptor, Plexin-A1, with off-track and vascular endothelial growth factor receptor type 2. Gen Dev 18:435-447.

Toyofuku T, Yoshida J, Sugimoto T, Yamamoto M, Makino N, Takamatsu H, Takegahara N, Suto F, Hori M, Fujisawa H, Kumanogo A, Kikutani H (2008) Repulsive and attractive semaphorins cooperate to direct the navigation of cardiac neural crest cells. Dev Biol 321:251-262.

Winberg ML, Mitchell KJ, Goodman CS (1998) Genetic analysis of the mechanisms controlling target selection: complementary and combinatorial functions of netrins, semaphorins, and IgCAMs. Cell 93:581591. 